\title{
Correlation between $K$ complex, periodic leg movements (PLM), and myoclonus during sleep in paraplegic adults before and after an acute physical activity
}

\author{
MT Mello ${ }^{1}$, AC Silva $^{2}$, AD Rueda ${ }^{3}$ D Poyares $^{4}$ and S Tufik ${ }^{5}$ \\ ${ }^{1}$ Graduate student of UNIFESP-EPM - Department of Psychobiology Universidade Federal de Goiás-Catalão; \\ ${ }^{2}$ Department of Physiology - UNIFESP; ${ }^{3}$ Associação Fundo de Incentivo à Psicofarmacologia $($ AFIP $) ;{ }^{4}$ Graduate \\ student of UNIFESP-EPM - Department of Psychobiology Associação Fundo de Incentivo à Psicofarmacologia; \\ ${ }^{5}$ Department of Psychobiology - UNIFESP; Universidade Federal de São Paulo - UNIFESP Department of \\ Psychobiology, Rua Botucatu, 862 - I andar - Vila Clementino - São Paulo - SP - Brazil
}

\begin{abstract}
$\mathrm{K}$ complex is the characteristic wave of stage II of sleep. The relationship between periodic limb movements (PLM) and the restless legs syndrome (RLS), and the incidence of $\mathrm{K}$ complexes and alpha activity has been previously described. The aim of the present study was to evaluate the effect of an acute physical activity upon K complex, PLM, and myoclonus during sleep in individuals who were paraplegic. We evaluated 84 polysomnograms from 28 volunteers with a spinal cord injury at the level of T7-T12, obtained during three consecutive nights. On day 3, the volunteers were submitted to a test of maximum effort (manual cycloergometer, with the equipment Cybex Met 300, with a progressive load increase of $12.5 \mathrm{w}$, every $2 \mathrm{~min}$ ). The analysis of the polysomnographic recordings showed a positive correlation between the incidence of $\mathrm{K}$ complex and limb movements on nights 1, 2 and 3 . Similarly, a correlation between the incidence of $\mathrm{K}$ complex and myoclonus was observed on nights 1,2 and 3 . An increased incidence of the total $\mathrm{K}$ complex was seen on night $3,36 \mathrm{~h}$ after the test of maximum effort. Both total $\mathrm{K}$ complex and $\mathrm{K}$ complex/h were reduced on night 2, compared to basal recording (night 1). There was a reduction of sleep latency on night 2 , whereas total sleeping time increased progressively on night 3 , as well as REM phase on nights 2 and 3 . These findings indicate that physical activity can affect or modulate the incidence of $\mathrm{K}$ complex and suggest that a positive correlation between PLM and K complex may occur in those who are paraplegic from a spinal cord injury. In conclusion, sleep can be consolidated after physical activity.
\end{abstract}

Keywords: sleep; K complex; periodic leg movements; myoclonus; paraplegic; physical activity

\section{Introduction}

The $\mathrm{K}$ complex is the characteristic wave of stage II of NREM sleep and consists of a negative acute wave followed, immediately, by a positive component and generally accompanied by fusiform waves. K-complex duration does not exceed $0.5 \mathrm{~s}$, with a frequency of 12 to 14 cycles. ${ }^{1}$ This event can also be elicited, during sleep, by external or internal stimuli, specially auditory ones. Ontogenetically, K complex appears between the third and the sixth months of age., ${ }^{2,3}$ The wave amplitude does not exceed $200 \mu \mathrm{V}$ from this period up to 5 years of age. ${ }^{4-6} \mathrm{~K}$ complex waves are indicative of a more superficial sleep, ${ }^{7}$ and is associated with epileptic events, ${ }^{8}$ incidence of periodic limb movements (PLM) and restless legs syndrome (RLS) during sleep. ${ }^{9}$

Correspondence: MT de Mello
Clinical manifestations of RLS can be related to insomnia, hypersomnia, narcolepsy, and sleep apnea. ${ }^{10}$ However, the occurrence of RLS as well as the decrease of symptoms and frequency of RLS can be affected by some factors, such as fatigue, caffeine-rich drinks, and exposure to cold during certain periods of the year. ${ }^{9}$ Most patients with RLS exhibit stereotypes in the legs during sleep, corresponding to PLM. ${ }^{11}$ Therefore, the incidence and origin of PLM are similar to those of RLS. ${ }^{12}$ PLM has been originally described as a rhythmic extension of the legs followed by dorsiflexion of the ankle, with knee flexion and a high generalized motor activation in the legs. The mean duration of each movement ranges from 0.5 to $5.0 \mathrm{~s}$, with a frequency of one movement at $20-40 \mathrm{~s}$ intervals. However, the duration can vary from some minutes to some hours, according to the criteria established by the American Sleep Disorder Associa- 
tion (ASDA). In general, the episodes cause some arousals, decreased sleep quality and efficiency, and higher incidence during the first third of sleep. ${ }^{9}$ The occurrence of PLM and RLS in patients submitted to general epidural anesthesia (spinal cord) ${ }^{13}$ and the presence of the plantar cutaneous reflex in extension (Babinski's sign) during NREM sleep ${ }^{14-16}$ have been described previously, suggesting that these manifestations can be of peripheral origin.

Spontaneous reports of sleep disorders are frequent amongst those who are paraplegic. ${ }^{17}$ Several sleep characteristics and the incidence of PLM, myoclonus, and RLS have been studied in those with paraplegia from a spinal cord injury. ${ }^{17-20}$ Physical activity appears to reduce sleep disorders in this population since an epidemiological survey ${ }^{17,18}$ showed that physically active people with paraplegia had a low incidence of snoring and a sleep pattern similar to what is reported for the general population. However, the data obtained from direct evaluation (computerized polysomnography) ${ }^{19}$ differ from those obtained in a previous study ${ }^{17}$ with a higher incidence of PLM in physically active individuals. The baseline direct evaluation did not reveal any difference in the rate of $\mathrm{PLM} / \mathrm{h}$ between physically active and non-active people with paraplegia. However, a decrease in this rate was found after physical activity in both groups. ${ }^{17}$

\section{Aim}

The present study aimed to study the influence of an acute physical activity upon sleep ( $\mathrm{K}$ complexes, myoclonus, PLM) in paraplegics.

\section{Methodology}

Contact with volunteers was established through associations for physically disabled (handicapped subjects). They were included in the study after clinical evaluation. The inclusion criteria was the following: volunteers were submitted to a clinicalneurological evaluation, with complimentary radiological examinations, in addition to computerized tomography confirming total spinal cord injury at T7-T12 level, affecting the superior motor neuron. Volunteers should have had the lesion for at least 1 year; all volunteers should have consented to be hospitalized for 5 days at the Sleep Laboratory at the Center of Clinical Psychobiology of the Universidade Federal de São Paulo.

Twenty eight volunteers were evaluated based on 84 polysomnograms obtained during 3 consecutive nights at the sleep laboratory. However, whole night sleep polysomnographic recording was obtained on nights 1 , 2 and 3. Before the beginning of the study, volunteers slept in the laboratory in order to adapt to the equipment and the setting. The polysomnographic recording was performed according to the standardized criteria for the classification of sleep stages described by Rechtschaffen \& Kales (1968), ${ }^{1}$ and the electroencephalograms were obtained according to the international system $10-20 .^{21}$ Polysomnography (Oxford/Medilog/8 channels) included two electroencephalographic (EEG), four electromyographic (two on the legs (EMGI), one on the arm (EMGa), and one on the submandibular region (EMGs)) and two oculogram recordings (EOG). An arm electromyogram was used for comparative purposes.

The hospitalization schedule was the following:

First day - Laboratory tests, clinical-neurological evaluation and neuroimaging tests; adaptation night, including polysomnographic evaluation.

Second day - Polysomnographic evaluation (recording night 1).

Third day - Evaluation of the functional capacity and risks for cardiac failure during physical activity (Test of Maximum Effort), using a manual cycloergometer Cybex Met 300, with increments of $12.5 \mathrm{w}$ up to exhaustion at $2 \mathrm{~min}$ intervals; polysomnographic evaluation (recording night 2/ $12 \mathrm{~h}$ after physical activity).

Fourth day - Polysomnographic evaluation (recording night $3 / 36 \mathrm{~h}$ after physical activity).

Fifth day - Volunteers checked out. Volunteers were not required to attend the laboratory after discharge.

The Spearman Rank Order Correlation Test was used to establish a possible correlation between $\mathrm{K}$ complex/myoclonus and $\mathrm{K}$ complex/limb movements. Wilcoxon Matched Pairs Test and Student's $t$ test were used to compare the frequencies of $\mathrm{K}$ complex and PLM, total sleeping time, sleep latency, and total REM time between nights 1 and 2 and nights 1 and 3, with the level of significance set at $P \leqslant 0.05$.

Neurological evaluation (including clinical examination and neuroimaging tests) aimed to determine the level of spinal cord injury and volunteers' impairment. They aimed to support the functional diagnosis rather than to compare the data obtained.

\section{Results}

The mean age of the volunteers was $29.50 \pm 9.2$ years. Comparison of the data obtained on nights $1,2(12 \mathrm{~h}$ after the maximum exercise test), and 3 ( $36 \mathrm{~h}$ after the maximum exercise test) revealed a significant correlation between the incidence of $\mathrm{K}$ complex and PLM $(P \leqslant 0.0001$ (R: 0.66); $P \leqslant 0.007$ (R: 0.79); $P \leqslant 0.0007$ (R: 0.86)), respectively (Spearman Order Correlation Test) (Figure 1 and Table 1).

Correlation between incidence of $\mathrm{K}$ complex and myoclonus during sleep was statistically significant $(P \leqslant 0.0001$ (R: 0.96); $P \leqslant 0.0001$ (R: 0.93); $P \leqslant 0.0001$ (R: 0.91)) on nights 1, 2 and 3, respectively (Spearman Order Correlation Test) (Table 1).

Table 2 shows the various parameters obtained in the polysomnographic recordings. Differences on the total number of $\mathrm{K}$ complexes were observed between nights 1 and $2(P \leqslant 0.014)$ and nights 1 and $3(P \leqslant 0.02$, 


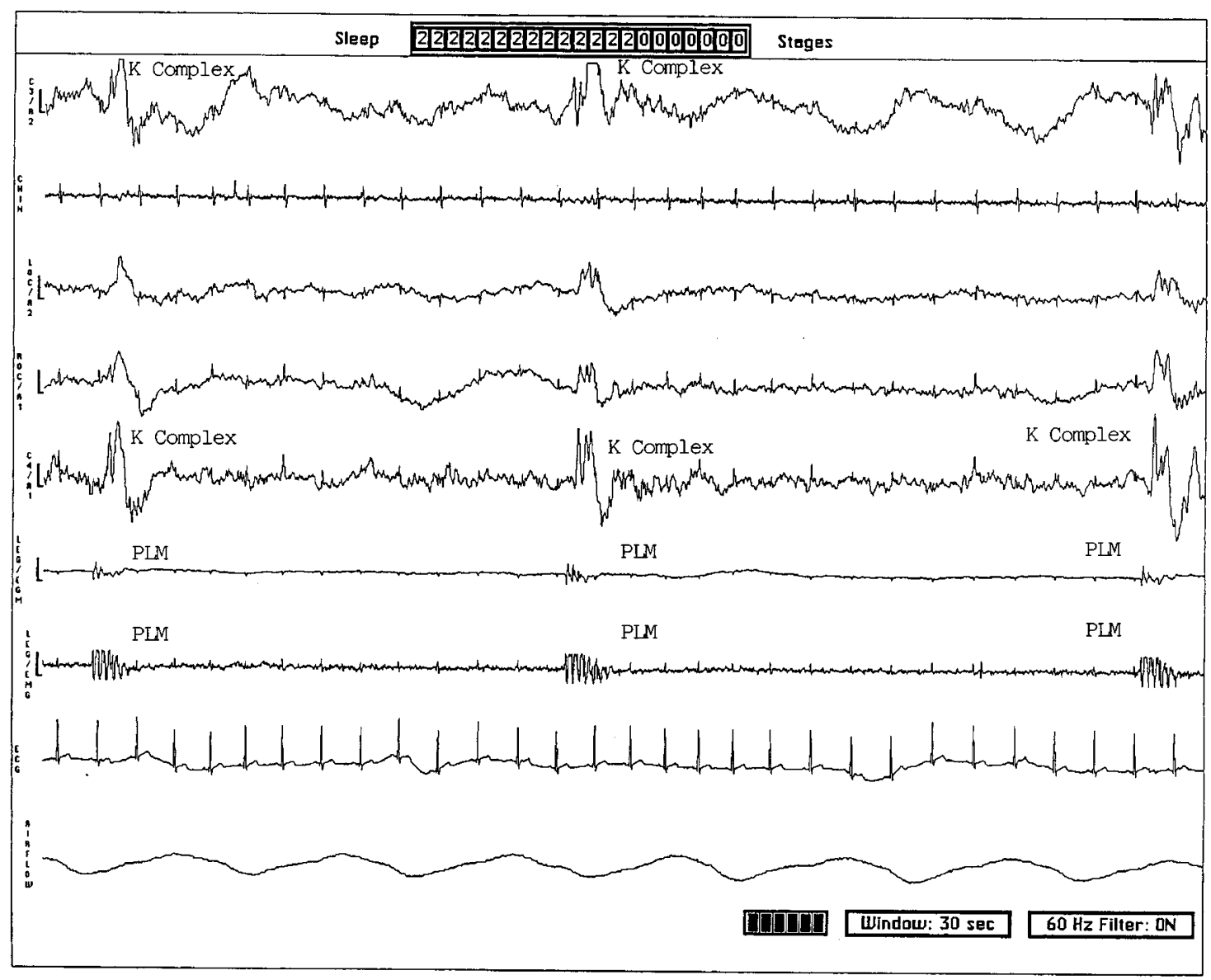

Figure 1 Correlation between the incidence of $\mathrm{K}$ complex and periodic leg movements

Table 1 Results of the correlations between $\mathrm{K}$ complex, myoclonus and $\mathrm{PLM} / \mathrm{h}$ during the different nights of polysomnographic recording

\begin{tabular}{lccc}
\hline & $\begin{array}{c}\text { Night 1 } \\
\text { (Baseline) }\end{array}$ & $\begin{array}{c}\text { Night 2 } \\
\text { (12h after } \\
\text { exercise) }\end{array}$ & $\begin{array}{c}\text { Night 3 } \\
\text { (36h after } \\
\text { exercise) }\end{array}$ \\
\hline Total K complex & $\mathrm{R}=0.66$ & $\mathrm{R}=0.79$ & $\mathrm{R}=0.86$ \\
$\times \mathrm{PLM} / \mathrm{h}$ & $P<0.0001$ & $P<0.0007$ & $P<0.0007$ \\
Total K complex & $\mathrm{R}=0.96$ & $\mathrm{R}=0.93$ & $\mathrm{R}=0.91$ \\
$\times$ Myoclonus & $P<0.0001$ & $P<0.0001$ & $P<0.0001$ \\
\hline
\end{tabular}

Total $\mathrm{K}$ complex is the total number of occurrences during sleep; PLM/h is the index of number of PLM at each hour of sleep; myoclonus is the number of episodes during sleep

Wilcoxon Matched Pair Test). As for K complex/h of sleep, there was a reduction on night 2 (12 h after the physical activity), compared to night $1 \quad(P<0.05$, Student's $t$ test). In addition, the rate of $\mathrm{PLM} / \mathrm{h}$ on 3 (36 h after the maximum exercise test) was lower than that on night $1(P \leqslant 0.003$, Wilcoxon Matched Pairs test).
In regard to total sleeping time, a progressive increase was observed on night 3 , compared to night $1(P<0.04$, Student's $t$ test $)$. On the contrary, sleep latency was reduced on night 2 , compared to night 1 $(P<0.04$, Student's $t$ test $)$. Moreover, a progressive increase of time of REM phase was obtained on nights 2 and 3 , compared to night $1(P<0.05$, and $P<0.02$, respectively, Student's $t$ test).

\section{Discussion}

Literature data suggest that physical activity appears to reduce sleep disorders in those who are paraplegic. ${ }^{17,19}$ The occurrence of PLM during sleep in such individuals, ${ }^{17-20}$ can be useful to elucidate the origin of this disorder. Different hypotheses to explain the origin of PLM and different therapies have been described in the literature. ${ }^{9-12,22-24}$ However, the fact that PLM appear in subjects with spinal cord injury casts doubt on its central origin. Our results showed that following physical activity, both total number of $\mathrm{K}$ complex and $\mathrm{K}$ complex/h, in addition to sleep latency, were reduced. These findings indicate an improvement of sleep pattern after the test of 
Table 2 Mean \pm SD of several parameters evaluated in the polysomnography, recorded on the different nights of the study

\begin{tabular}{|c|c|c|c|c|}
\hline & $\begin{array}{l}\text { Night 1 } \\
\text { (Baseline) }\end{array}$ & $\begin{array}{c}\text { Night } 2 \\
\text { (12 h after exercise) }\end{array}$ & $\begin{array}{ll}\text { Night } 3 \\
\text { (36h } \\
\text { after exercise) }\end{array}$ & $\begin{array}{l}\text { Level of } \\
\text { significance }\end{array}$ \\
\hline Total K complex & $213.7 \pm 140.2$ & $184.1 \pm 160.41^{*}$ & $306.35 \pm 238.13 *$ & $\begin{array}{c}P<0.014 \text { (night } 2) \\
P<0.02 \text { (night } 3)\end{array}$ \\
\hline $\mathrm{K}$ complex $/ \mathrm{h}$ & $7.37 \pm 14.55$ & $1.7 \pm 3.33^{*}$ & $4.18 \pm 8.87$ & $P<0.003$ \\
\hline $\mathrm{PLM} / \mathrm{h}$ & $30.19 \pm 39.25$ & $21.03 \pm 39.26$ & $19.26 \pm 4.7 *$ & $P<0.003$ \\
\hline Total myoclonus & $64.29 \pm 84.06$ & $64.27 \pm 142.56$ & $60.99 \pm 101.02$ & N.S. \\
\hline Total sleeping time $(\min )$ & $397.88 \pm 63.1$ & $407.11 \pm 61.23$ & $417.05 \pm 48.66^{*}$ & $P<0.05$ \\
\hline Sleep latency $(\mathrm{min})$ & $22.62 \pm 28.93$ & $13.78 \pm 18.94^{*}$ & $16.84 \pm 17.28$ & $P<0.04$ \\
\hline Sleep efficiency & $84.91 \pm 12.19$ & $85.75 \pm 10.5$ & $87.98 \pm 9.74$ & N.S. \\
\hline Time of REM (min) & $86.21 \pm 31.32$ & $100.12 \pm 39.75^{*}$ & $101.01 \pm 28.6^{*}$ & $\begin{array}{l}P<0.05 \text { (night } 2) \\
P<0.02 \text { (night } 3)\end{array}$ \\
\hline
\end{tabular}

N.S. $=$ not significant

maximum effort. However, decreased incidence of $\mathrm{K}$ complex did not correlate with total time of stage II of sleep, since it remained constant during all recording nights.

The appearance of abnormal movements following a spinal cord injury suggests that this anatomical structure can contribute to the genesis of PLM due to inhibition or release of segments below the lesion. This hypothesis may explain the occurrence of PLM, associated with $\mathrm{K}$ complex, which is an event of central origin, in those who are paraplegic.

The decrease in PLM after physical activity can be due to the release of $\beta$-endorphins. In general this event is observed after physical exercise ${ }^{25-26}$ suggesting participation of the opiate system.

A positive correlation between $\mathrm{K}$ complex, PLM, and myoclonus has been previously reported. ${ }^{9}$ A similar relationship between $\mathrm{K}$ complex, PLM, and myoclonus was observed in a specific population of patients with a spinal cord injury. Moreover, simultaneous reduction of both parameters (K complex and PLM) occurred after physical activity.

\section{Acknowledgements}

Associação Fundo de Incentivo à Psicofarmacologia-AFIP, National Institute for the Development of Sports (INDESP) / Sports Agency / Ministry of Sports.

\section{References}

1 Rechtschaffen A, Kales A. Manual of standardized terminology technique, and scoring for sleep stages of human subjects. 4th edn., UCLA: Los Angeles 1978.

2 Metcalf DR. The effects of extrauterine experience on the ontogenesis of EEG sleep spindles. Psychosom Med 1969; 31: $393-399$

3 Metcalf DR, Mondale J, Burler FK. Ontogenesis of spontaneous K complexes. Psychophysiology 1971; 8: 340-347.

4 Lenard HG. The development of sleep spindles during the first two years of life. Neuropaediatre 1970; 1: 264-276.
5 Tanguay PE, Omitz EM, Kaplan A, Bozzo ES. Evolution of sleep spindles in childhood. Electroencephalogr Clin Neurophysiol 1975; 38: $175-181$.

6 Walczak T, Chokroverty S (1995). Electroencephalography, Electromyography and Electrooculography: General Principles and Basic Technology. In Sudhansu Chokroverty (ed). Sleep Disorders Medicine. Butterworth-Heinemann: Newoton 1995, pp. 504 .

7 Hoelscher TJ, Ware JC, McBrayer RH. Insomnia with periodic EEG arousals in the absence of apnea and myoclonus. Sleep Res 1989; 18: $245-245$.

8 Peled R, Lavie P. Paroxysmal awakenings from sleep associated with excessive daytime sleepiness: A form of nocturnal epilepsy. Neurology 1986; 36: $95-98$.

9 Montplaisir J, Godbout R, Pelletier G, Warnes H (1994). Restless legs syndrome and periodic limb movements during sleep. In: Kryger MH, Roth T, Dement WC (EDS). Principles and Practice of Sleep Medicine. 2nd edn., W.B. Saunders Company: Philadelphia 1994, pp. 589-597.

10 Coleman RM, Pollak CP, Weitzman ED. Periodic movements in sleep (nocturnal myoclonus): Relation to sleep disorders. Ann Neurol 1980; 8: 416-421.

11 Association of Sleep Disorders Centers, Sleep Disorders Classification Committee (Roffwarg HP, Chairman). Diagnostic classification of sleep and arousal disorders, 1st edn. Sleep 1979; 2: $1-137$.

12 Ekbom KA. Restless legs. Acta Med Scand Suppl 1945; 158: 123.

13 Watanabe S, Ono A, Naito H. Periodic leg movements during either epidural or spinal anesthesia in an elderly man without sleep-related (nocturnal) myoclonus. Sleep 1990; 13: 262-266.

14 Fujiki A, Shimizu A, Yamada Y, Yamamoto J, Kaneko Z. The Babinski reflex during sleep and wakefulness. Electroencephalogr Clin Neurophysiol 1971; 31: 610-613.

15 Smith RC. Relationship of periodic movements in sleep (nocturnal myoclonus) and the Babinski sign. Sleep 1985; 3: $239-243$.

16 Smith RC. Confirmation of Babinski-like response in periodic movements in sleep (nocturnal myoclonus). Biol Psychiat 1987; 22: $1271-1273$.

17 De Mello MT, Natal CL, Cunha JM, Tufik S. An epidemiologic study of sleep and complaints of subjects with spinal cord injury. Sleep Res 1994; 23: 356.

18 Takanori I, Kazuhiko H, Hitoshi T. Sleep-related periodic leg movements (nocturnal myoclonus) due to spinal cord lesion. $J$ Neurolog Sci 1991; 104: 13-18.

19 De Mello MT, Da Silva AC, Tufik S. Sleep study after acute physical activity in spinal cord injury. Sleep Res 1995; 24A: 391

20 Dickel MJ, Renfrow SD, Moore PT, Berry RB. Rapid eye movement sleep leg movements in patients with spinal cord injury. Sleep 1994; 17: $733-738$.

21 Jasper HH. The ten-twenty electrode system of the international federation. Electroencephalogr Clin Neurophysiol 1958; 10: 371 375 . 
22 Skirboll LR, Grace AA, Hommer DW. Peptide-monoamine coexistence studies of the action of cholecystokininlike peptides on the electrical activity of midbrain dopamine neurons. Neuroscience 1981; 6: $2111-2124$.

23 Lindvall O, Bjorklund A, Skagerberg G. Dopamine-containing neurons in the spinal cord: anatomy and some functional aspects. Ann Neurol 1993; 14: 255-260.

24 Montplaisir J, Godbout R, Poirier G, Bédard MA. Restless legs syndrome and periodic movements in sleep: Physiopathology and treatment with L-dopa. Clin Neuropharmacol 9: 456-463.
25 Twist DJ, Culpepper-Morgan JA, Ragnarsson KT, Petrillo CR, Kreek MJ. Neuroendocrine changes during functional electrical stimulation. Am J Phys Med Reab 1992; 71: 156-163.

26 Ransford, CP. A role for amines in the antidepressant effect of exercise. Med Sci Sports Exerc 1982; 14: 1-10. 